\title{
Activation of AKT/AP1/FoxM1 signaling confers sorafenib resistance to liver cancer cells
}

\author{
DONGJING YAN ${ }^{1 *}$, XIAOJING YAN ${ }^{2 *}$, XUFANG DAI $^{3,4^{*}}$, LINGXI CHEN $^{2}$, LIANGBO SUN $^{2}$, \\ TAO LI $^{2}$, FENGTIAN HE ${ }^{2}$, JIQIN LIAN ${ }^{2}$ and WANGWEI CAI ${ }^{1}$ \\ ${ }^{1}$ Department of Biochemistry and Molecular Biology, Hainan Medical College, Haikou, \\ Hainan 571199; ${ }^{2}$ Department of Biochemistry and Molecular Biology, Army Medical University, \\ Chongqing 400038; ${ }^{3}$ Department of Educational Science College, Chongqing Normal University; \\ ${ }^{4}$ Chongqing Key Laboratory of Psychological Diagnosis and Educational Technology \\ for Children with Special Needs, Chongqing 400047, P.R. China
}

Received December 5, 2018; Accepted June 6, 2019

DOI: 10.3892/or.2019.7192

\begin{abstract}
Sorafenib is the first-line drug used in the treatment of liver cancer; however, drug resistance seriously limits the clinical response to sorafenib. The present study investigated the molecular mechanisms of sorafenib resistance in liver cancer cells. The data indicated that forkhead box M1 (FoxM1) was significantly overexpressed in sorafenib-resistant cells, at the mRNA and protein levels. Knockdown of FoxM1 rendered drug-tolerant cells sensitive to sorafenib. Furthermore, FoxM1 was upregulated at the transcriptional level. Overexpression of c-jun was associated with the upregulation of FoxM1. The results of a reporter gene assay, electrophoretic mobility shift assay and chromatin immunoprecipitation assay demonstrated that there is an activator protein-1 (AP1) binding site in the promoter of FoxM1, located at -608 to -618 . Knockdown of c-jun significantly decreased the levels of FoxM1, accompanied by enhanced cell sensitivity to sorafenib. Furthermore, the activation of AKT contributed to the upregulation of c-jun and FoxM1. Inhibition of AKT using BEZ-235 markedly suppressed the upregulation of c-jun and FoxM1, and increased the sensitivity of drug-resistant cells to sorafenib in vitro and in vivo. The data indicated that the activation of
\end{abstract}

Correspondence to: Dr Jiqin Lian, Department of Biochemistry and Molecular Biology, Army Medical University, 30 Gaotanyan Street, Chongqing 400038, P.R. China

E-mail: lianjiqin@sina.com

Dr Wangwei Cai, Department of Biochemistry and Molecular Biology, Hainan Medical College, 3 Xueyuan Road, Haikou, Hainan 571199, P.R. China

E-mail: caiww591020@163.com

${ }^{*}$ Contributed equally

Key words: AKT, AP1, forkhead box M1, liver cancer, sorafenib, resistance the AKT/AP1/FoxM1 signaling axis is an important determinant of sorafenib tolerance.

\section{Introduction}

Liver cancer, the most common primary liver tumor, is the third leading cause of cancer mortality globally (1). Surgical resection, thermal ablation and liver transplantation are the current treatments for early-stage liver cancer (2). However, liver cancer is often diagnosed at an advanced stage with poor prognosis. Sorafenib, a multikinase inhibitor of mitogen-activated protein kinase/ERK, vascular endothelial growth factor (VEGF) receptor and platelet-derived growth factor, is the only approved drug available for the treatment of advance liver cancer (3). Sorafenib has a good tolerability profile and treatment leads to a longer median survival time (3). Unfortunately, its activity is limited by primary and acquired drug resistance (4). Thus far, the mechanisms of sorafenib resistance are not well established; therefore, it is crucial to determine the mechanisms associated with resistance and to develop additional therapeutic agents to enhance the effects of the drug.

Forkhead box M1 (FoxM1) is a member of the forkhead box transcription factor family. Previous studies have revealed that FoxM1 has an important role in the pathogenesis and progression of human cancers, including liver cancer $(5,6)$. Suppression of FoxM1 expression can lead to chromosome disaggregation, mitotic spindle defects, mitotic catastrophe and cell cycle arrest (7). As a key regulator of the G1/S and G2/M transition, FoxM1 regulates the expression of several cell cycle-associated factors, including $\mathrm{p} 21^{\mathrm{Cip} 1}$, cyclin $\mathrm{B}$, p2 $7^{\mathrm{Kip} 1}$, Aurora B kinase, survivin, CDC25B and polo-like kinase-1 $(8,9)$. Additionally, the phosphorylation of FoxM1 promotes its nuclear translocation and enhances its transcriptional activity during G2/M (10). Previous research has revealed that FoxM1 is a credible target for arresting cancer growth and progression. In tumor-bearing mice, knockdown of FoxM1 can significantly reduce tumor growth (11). By contrast, the overexpression of FoxM1 can markedly increase the size of tumors (11). FoxM1 can also promote tumor angiogenesis by enhancing VEGF expression at the transcriptional 
level (12) and suppression of FoxM1 inhibited angiogenesis in liver cancer (13). Additionally, senescence was induced in FoxM1-knockout embryonic fibroblasts, while $\mathrm{H}_{2} \mathrm{O}_{2}$-induced senescence was reversed by FoxM1 overexpression (14). Recent studies have indicated that the overexpression of FoxM1 may accelerate the development of acquired drug resistance (15-17). However, whether the overexpression of FoxM1 contributes to sorafenib resistance in liver cancer requires further investigation.

In the present study, FoxM1 was significantly upregulated in sorafenib-resistant liver cancer cells. Knockdown of FoxM1 increased the sorafenib sensitivity of drug-tolerant cells. Furthermore, a signaling axis, the AKT/activator protein-1 (AP1)/FoxM1 signaling pathway, was revealed to contribute to sorafenib resistance in liver cancer cells. Suppression of this axis using AKT inhibitor BEZ-235 increased the sensitivity of drug-tolerant cells to sorafenib in vitro and in vivo. The data indicated that the AKT/AP1/FoxM1 signaling axis is a critical determinant of sorafenib tolerance.

\section{Materials and methods}

Cell culture. Human liver cancer cell lines HepG2 and Huh7 cells were purchased from the American Type Culture Collection (ATCC), and cultured in high-glucose DMEM with $10 \% \mathrm{FBS}$, in a humid incubator with $5 \% \mathrm{CO}_{2}$. The two lines were originally tested by ATCC and passaged $<6$ months in the laboratory of Biochemistry and Molecular Biology of Hainan Medical College.

Establishment of sorafenib-resistant cells. The $\mathrm{IC}_{50}$ value of liver cancer cells to sorafenib was initially determined by the 4PL method as previously described (18). The equation is expressed as follows: $Y=\frac{a-d}{1+(X / c)^{6}+d}$; where $\mathrm{Y}$ is the response, and $\mathrm{X}$ is the concentration. The variable ' $\mathrm{a}$ ' is the bottom of the curve, and ' $d$ ' is the top of the curve. The variable ' $b$ ' is the slope factor, and ' $c$ ' is the concentration corresponding to the response midway between 'a' and 'd'. The cells were cultured in 6-well plates at $1 \times 10^{4}$ cells/well and incubated with sorafenib at a concentration just below their respective $\mathrm{IC}_{50}$ values. The concentration of sorafenib was slowly increased by $0.25 \mu \mathrm{mol} / 1$ per week. After 6-7 months, two sorafenib-resistant cell lines, termed 'HepG2-SR' and 'Huh7-SR', were obtained and were continuously maintained by culture in the presence of sorafenib.

Cell viability assay. Cell viability was assayed using a Cell Counting Kit-8 (CCK-8; Dojindo Molecular Technologies, Inc.). Briefly, the cells were seeded in triplicate in 96-well plates and underwent different treatments (including sorafenib at 5, 10, 15 and $20 \mu \mathrm{mol} / 1$ dose, sorafenib combined FoxM1 siRNA, sorafenib combined c-jun siRNA and sorafenib combined BEZ-235) for $48 \mathrm{~h}$, and then the optical density value at $450 \mathrm{~nm}$ was detected according to the manufacturer's instructions.

Western blot analysis. Cells were harvested and whole-cell lysates were prepared. The protein concentrations were measured using a bicinchoninic acid (BCA) protein assay kit (Beyotime Institute of Biotechnology). Subsequently, western blot analysis was performed as previously described (19). Anti-FoxM1 (dilution 1:1,000; cat. no. ab180710) and c-jun (dilution 1:1,000; cat. no. ab31419) primary antibodies were purchased from Abcam. Phosphorylated (p)-JNK (dilution 1:1,000; cat. no. 9255), p-AKT (dilution 1:1,000; cat. no. 4060), p-ERK (dilution 1:1,000; cat. no. 9101) antibodies were obtained from Cell Signaling Technology, Inc. GAPDH (dilution 1:5,000; cat. no. sc-137179) antibody was obtained from Santa Cruz Biotechnology, Inc.

Reverse transcription-quantitative PCR (RT-qPCR). Cells were lysed and total RNA was extracted with TRIzol reagent (Thermo Fisher) as previously described (19), and the first-strand cDNA was synthesized using M-MLV transcriptase (Invitrogen; Thermo Fisher Scientific, Inc.). qPCR was performed to detect the level of mRNA using SYBR qPCR master mix (Takara Biotechnology Co., Ltd.) in a 20- $\mu 1$ volume according to the manufacturer's instructions. FOXM1 was amplified using the forward primer, 5'-GCCATCAAC AGCACTGAGAG-3' and reverse primer, 5'-TGGGGTGAA TGGTCCAGAAG-3'. JUN was amplified using the forward primer, 5'-GAGCTGGAGCGCCTGATAAT-3' and reverse primer. 5'-CCCTCCTGCTCATCTGTCAC-3'.

Plasmid construction. To construct reporter and mutant reporter plasmids, FoxM1 genomic DNA was extracted from HepG2 cells. The promoter region of human FoxM1 $(-2,000$ to +100$)$ containing the AP1 binding site was amplified by PCR using the PrimeSTAR HS DNA polymerase (Takara Biotechnology Co., Ltd.), and then inserted into the pGL3-Basic vector (Promega Corp.). The recombinant plasmid was termed pGL3-FoxM1. The mutant plasmid containing the promoter without the AP1 binding site was constructed using an overlap primer and termed pGL3-FoxM1-mu.

Transfection assay. The small interfering RNAs against FoxM1, c-Jun and control siRNA were obtained from Santa Cruz Biotechnology, Inc. The cells were separately transfected with FoxM1 or c-jun siRNAs and control siRNA (Shanghai GenePharma Co., Ltd.) at $50 \mathrm{nM}$ using Lipofectamine ${ }^{\circledR} 2000$ (Invitrogen; Thermo Fisher Scientific, Inc.) according to the manufacturer's instructions.

Luciferase reporter assay. HepG2 cells were seeded in 48-well plates and cultured to $70-80 \%$ confluence. Then, the cells were co-transfected with pGL3-FoxM1/or pGL3-FoxM1-mu and monitor plasmid RL-PTK. After $36 \mathrm{~h}$, the cells were lysed, and the Firefly and Renilla luciferase activities were measured using the Dual-Luciferase Reporter System (Promega Corp.) according to the manufacturer's instructions. The transfection experiments were performed at least three times in triplicate. Data are presented as the fold induction after normalizing the luciferase activity of the tested sample to that of the corresponding control sample.

Nuclear protein extraction. Kits for nuclear protein extraction and BCA protein assay were purchased from Beyotime Institute of Biotechnology. HepG2 cells were seeded to 6-well plates at a density of $2 \times 10^{6}$ cells and cultured to $80 \%$ confluence 
followed by the appropriate treatments. Cells were washed in ice-cold PBS, and resuspended by pipetting up and down in $200 \mu \mathrm{l}$ ice-cold cell lysis buffer [10 mM HEPES ( $\mathrm{pH} 7.9$ ), $10 \mathrm{mM} \mathrm{KCl,} 0.1 \mathrm{mM}$ EDTA, $1 \mathrm{mM}$ dithiothreitol (DTT), $0.4 \%$ IGEPAL, $2 \mu \mathrm{g} / \mathrm{ml}$ aprotinin, $1 \mathrm{mM}$ PMSF, $250 \mu \mathrm{g} / \mathrm{ml}$ benzamidine, $2 \mu \mathrm{g} / \mathrm{ml}$ leupeptin]. After incubation on ice for $15 \mathrm{~min}$, cell lysates were centrifuged at $12,000 \mathrm{x} \mathrm{g}$ for $5 \mathrm{~min}$ at $4^{\circ} \mathrm{C}$ and the supernatants (cytoplasm + membrane extract) were discarded. Nuclear pellets were then resuspended in $50 \mu \mathrm{l}$ nuclear extraction buffer (0.4 M NaCl, 20 mM HEPES pH 7.9, $1 \mathrm{mM}$ EDTA, $1 \mathrm{mM}$ DTT and $1 \mathrm{mM}$ PMSF). After vigorous shaking at $4^{\circ} \mathrm{C}$ for $30 \mathrm{~min}$, the nuclear extracts were centrifuged at $12,000 \mathrm{x}$ g for $10 \mathrm{~min}$ at $4^{\circ} \mathrm{C}$, and the supernatants for the nuclear protein were collected. The protein concentration was quantified using a BCA protein assay kit.

Electrophoretic mobility shift assay (EMSA). The EMSA kit was obtained from Pierce (Thermo Fisher Scientific, Inc.). Cells were harvested for nuclear extraction using a nuclear and cytoplasmic extraction kit (Thermo Fisher Scientific, Inc.). The probe sequences were as follows: AP1: 5'-GAC TGGTTGACTAAGTCAAT-3'. Mut AP1: 5'-GACTGGCCT ACCGGGTCAAT-3'. Biotin-5'-end-labeled and unlabeled, sense and antisense oligonucleotides were synthesized. The oligonucleotides were annealed to generate double-stranded probes. EMSA was performed by preincubating $3 \mu \mathrm{g}$ nuclear extract with a mixture containing $1 \mu \mathrm{g}$ poly $\mathrm{dI}: \mathrm{dC}$ and $2 \mu \mathrm{l}$ binding buffer on ice for $10 \mathrm{~min}$. Then, $20 \mathrm{fmol}$ biotin-labeled double-stranded probe was added to the mixture and incubated at room temperature for another 30 min. Competitive EMSA experiments were conducted by incorporating excess concentrations of the unlabeled probe in the pre-incubation step of the assay. DNA-protein complexes were resolved on a non-denaturing $5 \%$ polyacrylamide gel in $0.5 \mathrm{X}$ Tris-borate-EDTA. After electrophoresis, the samples were transferred onto Biodyne B precut modified nylon membranes (Thermo Fisher Scientific, Inc.). The membranes were cross-linked in a UV transilluminator for $15 \mathrm{~min}$ and then were incubated with blocking buffer and streptavidin-horseradish peroxidase conjugates. Bound conjugates were detected using a molecular imager (ChemiDoc XRS+; Bio-Rad Laboratories).

Chromatin immunoprecipitation assay (ChIP). EZ ChIP ${ }^{\mathrm{Tм}}$ Chromatin Immunoprecipitation Kit (EMD Millipore) was used to perform ChIP assays. In brief, cells were crosslinked using $4 \%$ formaldehyde for 10 min followed by cell collection and sonication with a predetermined power to yield genomic DNA fragments of 200-1,000 bp. Antibodies (8 $\mu \mathrm{g}$; Abcam) were immobilized on Protein A/G magnetic beads (Life Technologies; Thermo Fisher Scientific, Inc.) by overnight incubation. The magnetic beads were washed to remove unconjugated antibody and mixed with $8 \mu \mathrm{g}$ of sonicated chromatin. After an overnight incubation, magnetic beads were washed, and bound DNA was purified. PCR was then performed using equal amounts of IN (input) and IP (immunoprecipitated sample) DNA. The primers for PCR were as follows: forward, 5'-GGAAAGAACCTTGTCTGCC-3' and the reverse, 5'-GAC TAAGTTCCTTTGAGGGC-3'. PCR products were analyzed by $15 \%$ agarose gel electrophoresis.
Animal experiments. In vivo experiments were performed using 30 male nude mice (5-6 weeks old; 20-25 g body weight) purchased from the Beijing Vital River Experimental Animals Co., Ltd. Mice were housed in an air-conditioned atmosphere under a 12-h light/dark cycle and given free access to food and water. The mice were subcutaneously inoculated with $0.2 \mathrm{ml}$ cell suspension $\left(2 \times 10^{6}\right.$ cells, HepG2-SR/Huh7-SR or HepG2-SR/Huh7-SR transfected with FoxM1 siRNA) using a sterile 22-gauge needle. When tumors reached $\sim 100 \mathrm{~mm}^{3}$, the mice were randomized into 6 groups with 5-8 mice per group. The groups with FoxM1 siRNA transfection were treated with sorafenib (30 mg/kg/day orally) and the other groups were treated with sorafenib or sorafenib combined BEZ-235 (12.5 mg/kg/day orally). The tumor sizes and animal body weights were measured twice weekly. After 1 week, tumors from a single mouse from each group were dissected. Tumor tissues were processed for immunoblotting as previously described (19). All animal experiments were performed according to the protocol approved by the Army Medical University Guidelines for Use and Care of Animals.

Statistical analysis. The data were expressed as the mean \pm SD. Comparisons between two groups were performed using one-way analysis of variance (ANOVA) followed by Dunnett's test. $\mathrm{P}<0.05$ was considered to indicate a statistically significant difference.

\section{Results}

Establishment of sorafenib-resistant cell models. To investigate the mechanisms of sorafenib resistance in liver cancer, HepG2 and Huh7 cells were chronically exposed to sorafenib. Two different sorafenib-resistant cell lines were established as previously described (20). As revealed in Fig. $1 \mathrm{~A}$, the $\mathrm{IC}_{50}$ value of parental cells was $\sim 6.2 \mu \mathrm{mol} / 1$, whereas the $\mathrm{IC}_{50}$ was $>10 \mu \mathrm{mol} / 1$ in sorafenib-resistant cells. In the clonogenic assay, no parental cell colonies were present after treatment with $10 \mu \mathrm{mol} / 1$ sorafenib for 1 week, whereas numerous sorafenib-resistant cell colonies survived under the same conditions (Fig. 1B). Additionally, the levels of proliferating cell nuclear antigen (PCNA) were significantly higher in sorafenib-resistant cells than in the parental cells (Fig. 1C). These results indicated that the sorafenib-resistant liver cancer cell models had been established successfully.

FoxM1 is upregulated in sorafenib-resistant liver cancer cells and involved in sorafenib resistance. Since FoxM1 has an important role in drug resistance, the expression of FoxM1 in liver cancer cells was determined. Compared with the expression in parental cells, the level of FoxM1 in sorafenib-resistant cells was significantly increased, both at the protein and mRNA levels (Fig. 2A and B). Furthermore, knockdown of FoxM1 significantly decreased the resistance of sorafenib in sorafenib-resistant liver cancer cells (Fig. 2C and D). These data indicated that the upregulation of FoxM1 has a key role in liver cancer resistance to sorafenib.

APl enhances FoxM1 expression at the transcriptional level in sorafenib-resistant liver cancer cells. Since FoxM1 was 

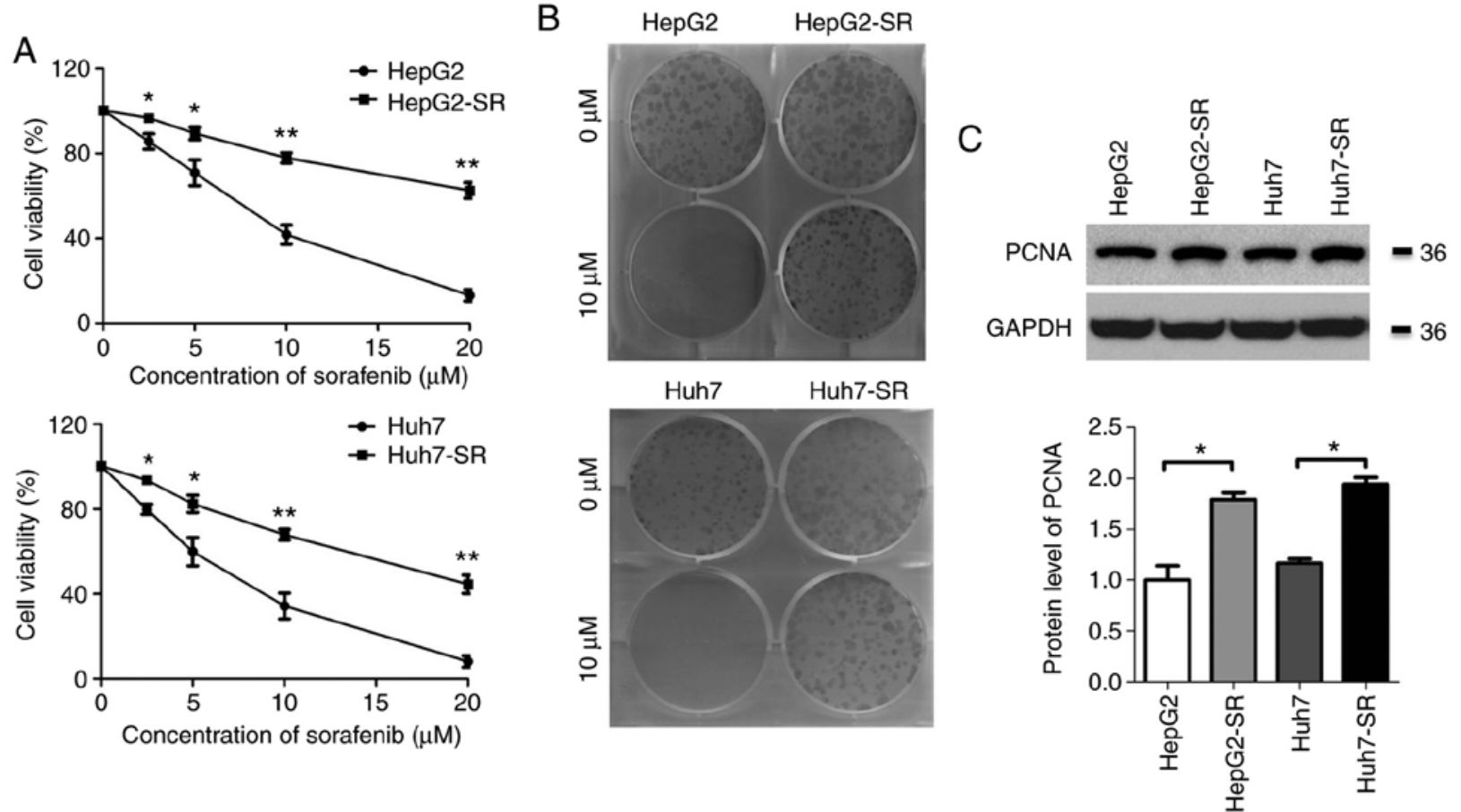

Figure 1. Sorafenib-resistant cell models are established. (A) The parent cell lines HepG2 and HuH-7 or sorafenib-resistant cell lines HepG2-SR and Huh7-SR were exposed to sorafenib at increasing concentrations for $48 \mathrm{~h}$. Then the cell viability was assessed by CCK- 8 kit. The experiment is representative of at least three independent experiments. ${ }^{*} \mathrm{P}<0.05$ and ${ }^{* *} \mathrm{P}<0.01$. (B) HepG2/HepG2-SR and HuH-7/Huh7-SR cells were passaged into 6-well plates and treated with DMSO control or $10 \mu \mathrm{M}$ sorafenib. Media with drugs was changed every 7 days and colonies were stained. The experiment is representative of at least three independent experiments. (C) The protein level of PCNA was detected by western blotting and quantified using Quantity One software (Bio-Rad Laboratories). The data were expressed as the fold change against the control group and are presented as the mean $\pm \mathrm{SEM}$. ${ }^{*} \mathrm{P}<0.05$.
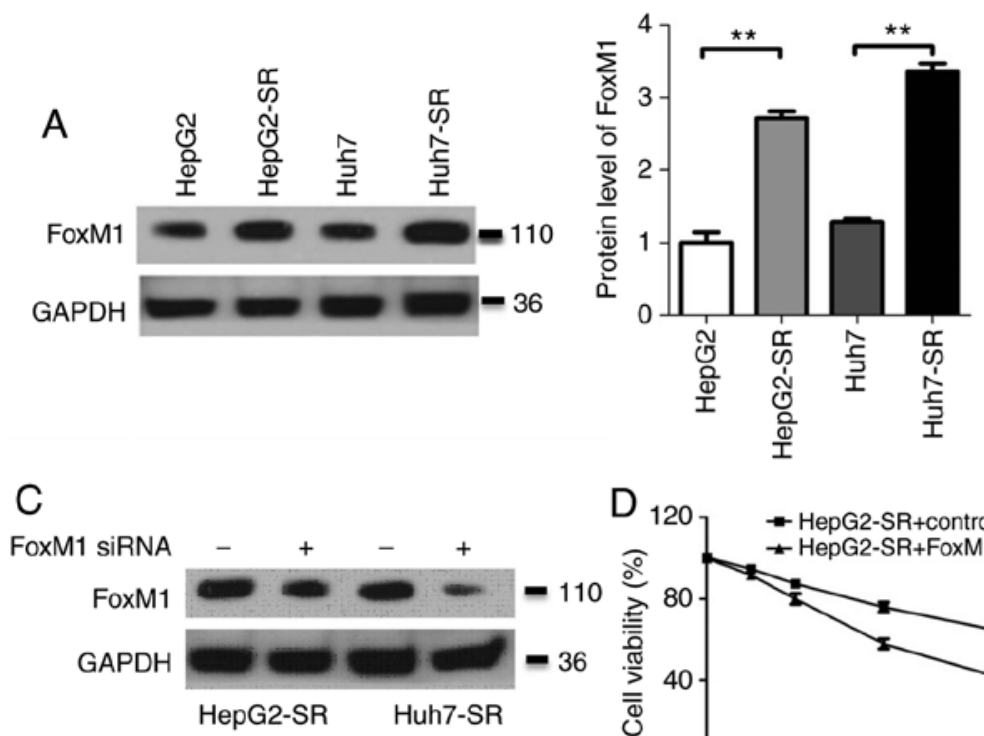
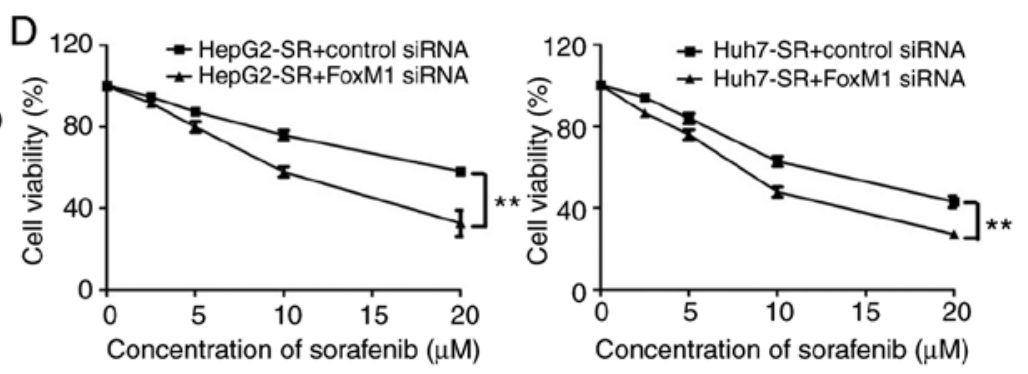

Figure 2. FoxM1 is upregulated in sorafenib-resistant liver cancer cells and contributed to sorafenib resistance. (A) The protein level of FoxM1 was detected by western blotting and quantified using Quantity One software. (B) The mRNA level of FoxM1 was assessed by qPCR in HepG2/HepG2-SR and HuH-7/Huh7-SR cells. (C) The effect of FoxM1 silencing was analyzed by western blotting in HepG2-SR and Huh7-SR cells. (D) The HepG2-SR and Huh7-SR cells were transfected with control siRNA or FoxM1 siRNA, and then were exposed to sorafenib at increasing concentrations for 48 h. Then the cell viability was measured using a CCK-8 kit. The parent HepG2 and HuH-7 cells were used as control. The experiment is representative of at least three independent experiments. ${ }^{* *} \mathrm{P}<0.01$. FoxM1, forkhead box M1; siRNA, small interfering RNA.

upregulated at the mRNA and protein levels, the activity of the FoxM1 promoter in sorafenib-resistant liver cancer cells was examined. The FoxM1 promoter fragment was cloned to construct a luciferase reporter plasmid. As revealed in 

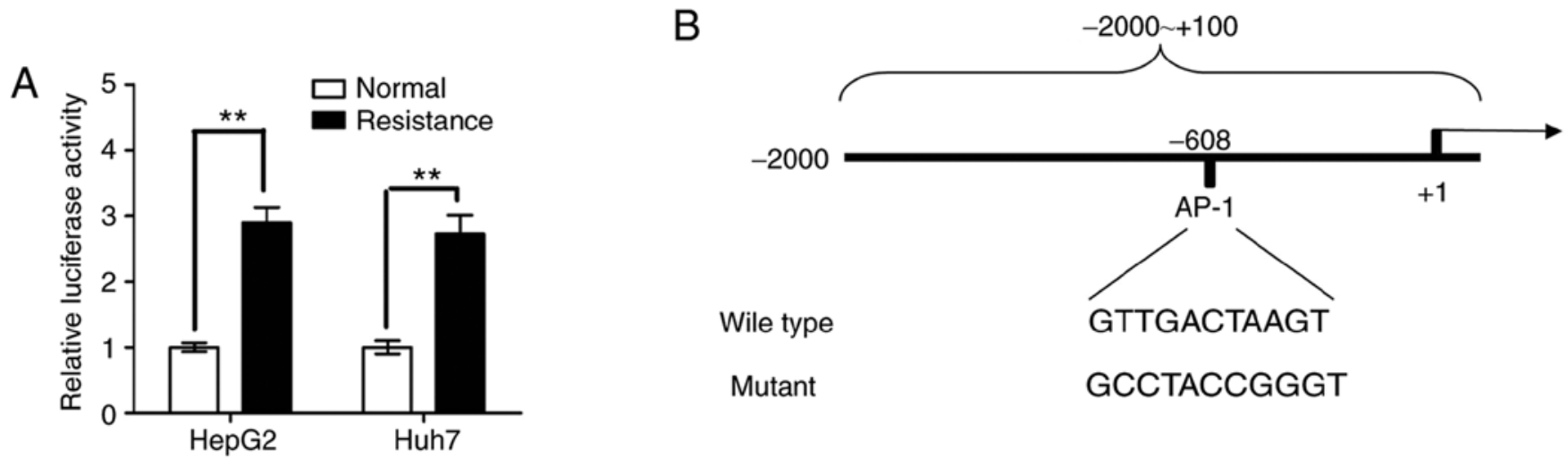

Mutant GCCTACCGGGT
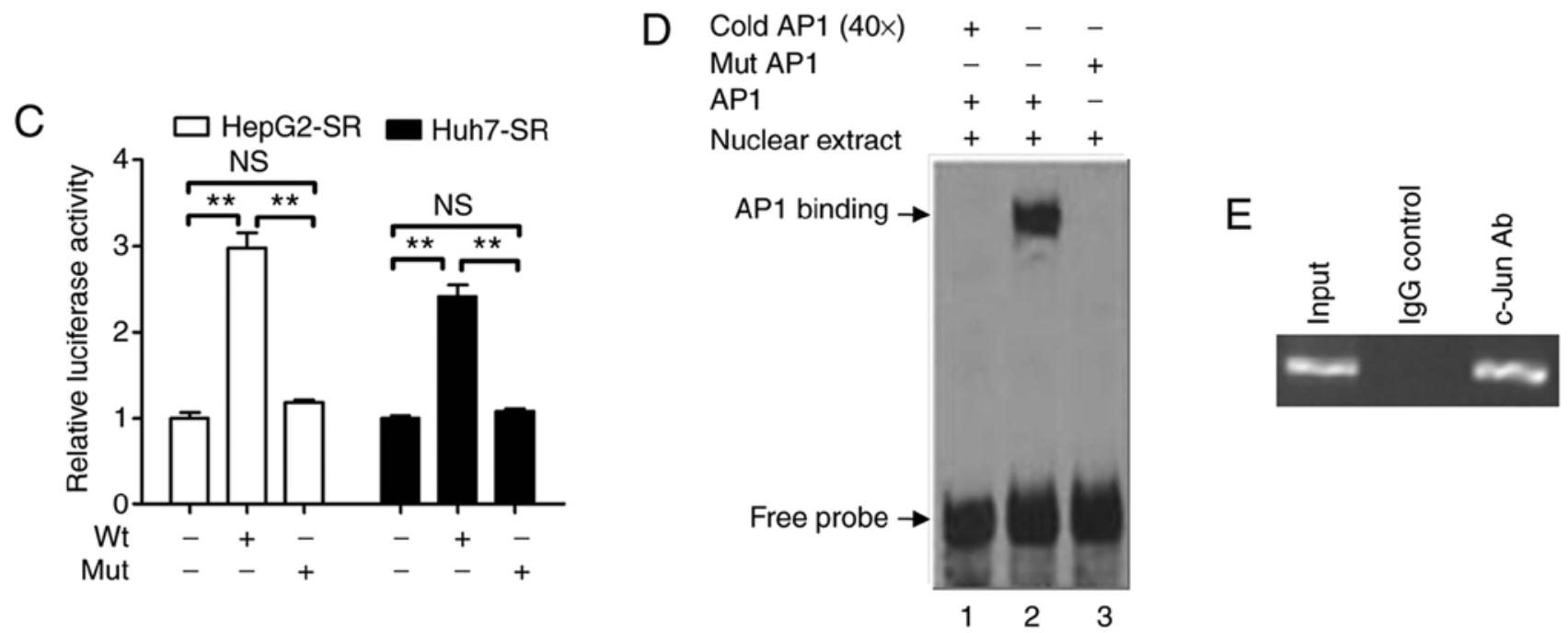

Figure 3. AP1 enhances FoxM1 expression at the transcriptional level in sorafenib-resistant liver cancer cells. (A) After transfection of HepG2/HepG2-SR and HuH-7/Huh7-SR cells with pGL3-FoxM1 for $36 \mathrm{~h}$, the luciferase activity was assayed using the Dual-Luciferase Reporter System and normalized to the control. ${ }^{* *} \mathrm{P}<0.01$. (B) Schematic representation of the FoxM1 promoter region containing the putative binding sites for AP1. The region $(-2,000$ to +100$)$ containing the wild-type or mutant AP1 binding site was cloned into the pGL3-Basic reporter vector and was named pGL3-FoxM1 or pGL3-FoxM1-mut. (C) After transfection with pGL3-FoxM1 or pGL3-FoxM1-mut for $36 \mathrm{~h}$ in HepG2-SR and Huh7-SR cells, the luciferase activity was assayed using the Dual-Luciferase Reporter System and normalized to the control. ${ }^{* *} \mathrm{P}<0.01$. (D) The nuclear extracts from the HepG2 cells were incubated with the indicated probes. Lane 1, labeled probe, nuclear extracts, and 50-fold unlabeled probe; lane 2, labeled probe with nuclear extracts; lane 3, labeled mutant probe and nuclear extracts. The protein-DNA complexes formed are identified by arrows. (E) Chromatin immunoprecipitation assay with chromatin isolated from HepG2 cells. Antibody directed against c-Jun was used for immune precipitation, using IgG as a negative control. Final DNA extractions were amplified by PCR with the primer pairs covering the binding site of AP1 in the FoxM1 promoter region. Total extract (input) was used as a positive PCR control. Representative data from three experiments are presented. The experiment displayed is representative of at least three separate experiments. AP1, activator protein-1; FoxM1, forkhead box M1; ns, not significant.

Fig. 3A, the activity of the FoxM1 promoter was significantly higher in sorafenib-resistant liver cancer cells than in parental liver cancer cells. Furthermore, bioinformatic analysis revealed that there is a transcription factor AP1 binding site at -608 to -618 of the FoxM1 promoter (Fig. 3B). A mutant luciferase reporter plasmid was constructed in which the AP1 binding site in the FoxM1 promoter was mutated (Fig. 3B). As revealed in Fig. 3C, the promoter activity of the mutant luciferase reporter plasmid was markedly lower than that of the wild-type luciferase reporter plasmid in sorafenib-resistant liver cancer cells. Furthermore, EMSA demonstrated that the wild-type AP1-binding sequence (GTTGACTAAGT), but not the mutant fragment (GCCTACCGGGT), could bind to the protein in nuclear extracts from sorafenib-resistant liver cancer cells, and this binding could be blocked by the addition of cold AP1 probe (Fig. 3D). Furthermore, the ChIP assay revealed that the FoxM1 promoter fragment could be amplified by PCR using c-jun antibody-precipitated chromatin
(Fig. 3E). These data demonstrated that AP1 enhanced the FoxM1 promoter activity in sorafenib-resistant liver cancer cells.

Knockdown of c-jun suppresses the expression of FoxM1 and reduces the sorafenib resistance of liver cancer cells. The expression of c-jun in liver cancer cells was assessed.Compared to the expression in parental liver cancer cells, the level of c-jun was markedly increased in sorafenib-resistant liver cancer cells (Fig. 4A). Furthermore, knockdown of c-jun significantly suppressed the expression of FoxM1 and downregulated the promoter activity of FoxM1 in sorafenib-resistant liver cancer cells (Fig. 4B and C). Moreover, knockdown of c-jun also significantly reduced the resistance of sorafenib-resistant liver cancer cells to sorafenib (Fig. 4D). These results indicated that the overexpression of c-jun, at least partly, contributed to the upregulation of FoxM1 and sorafenib resistance in liver cancer cells. 


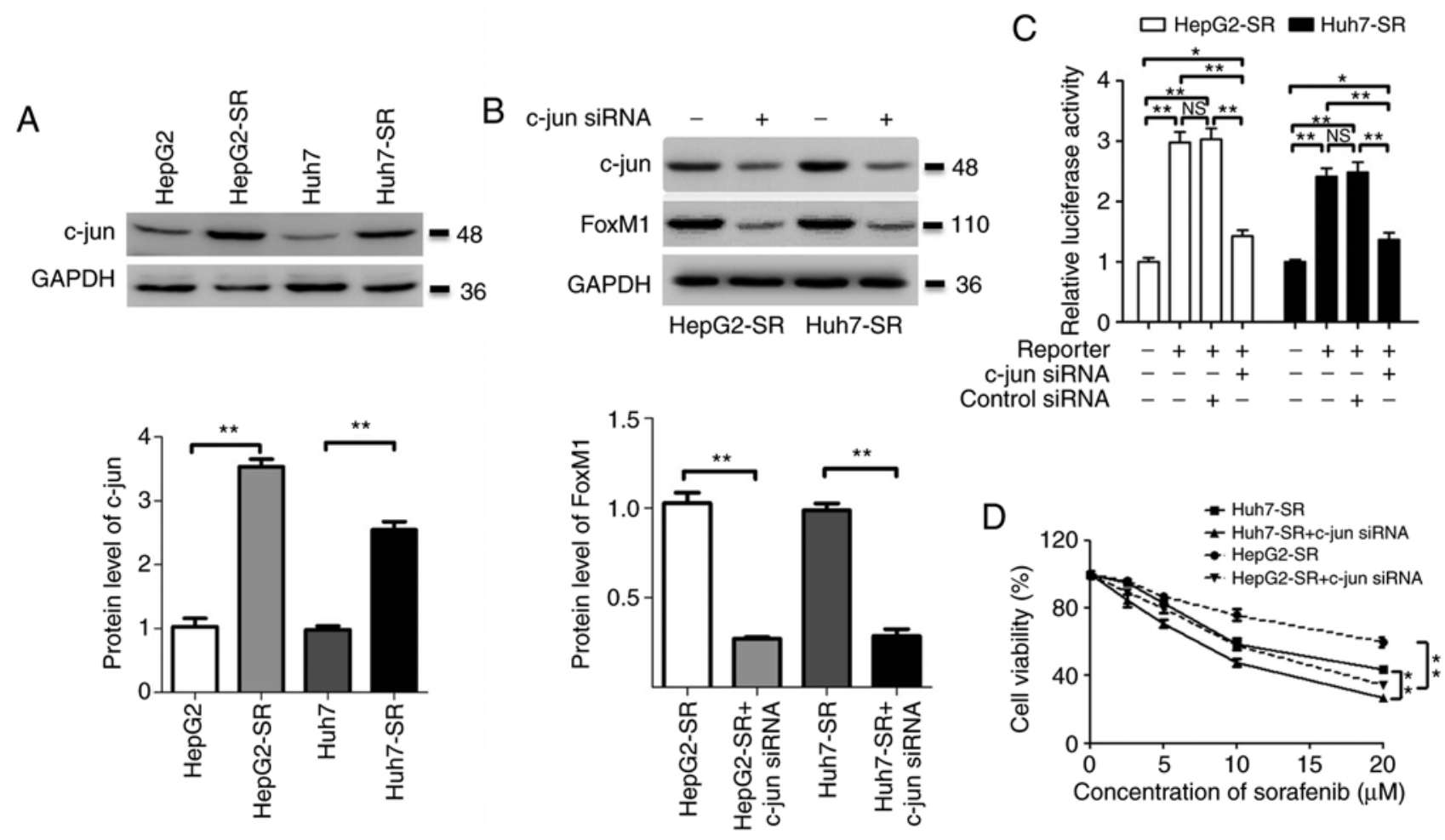

Figure 4. Knockdown of c-jun suppresses the expression of FoxM1 and reduces the resistance of sorafenib-resistant liver cancer cells to sorafenib. (A) The protein level of c-jun was detected by western blotting and quantified using Quantity One software in HepG2/HepG2-SR and HuH-7/Huh7-SR cells. ${ }^{* *} \mathrm{P}<0.01$. (B) HepG2-SR and Huh7-SR cells were transfected with control siRNA or c-jun siRNA, then the protein level of c-jun and FoxM1 were analyzed by western blotting and quantified using Quantity One software. ${ }^{* *} \mathrm{P}<0.01$. (C) HepG2-SR and Huh7-SR cells were transfected with control vector or pGL3-FoxM1, combined with control siRNA or c-jun siRNA, and then the luciferase activity was assayed using the Dual-Luciferase Reporter System and normalized to the control. ${ }^{*} \mathrm{P}<0.05$ and ${ }^{* *} \mathrm{P}<0.01$. (D) HepG2-SR and Huh7-SR cells were transfected with control siRNA or c-jun siRNA, and then were exposed to sorafenib at increasing concentrations for $48 \mathrm{~h}$. Then the cell viability was measured by a CCK- 8 kit. The experiment presented is representative of at least three separate experiments. ${ }^{* *} \mathrm{P}<0.01$. FoxM1, forkhead box M1; ns, not significant; siRNA, small interfering RNA.

Activation of AKT activates the c-jun/FoxM1 signaling axis in sorafenib-resistant liver cancer cells. The activity of several signaling pathways upstream of c-jun was determined. Consistent with a previous study (3), ERK activity (the ratio of p-ERK to t-ERK) was suppressed in sorafenib-resistant liver cancer cells (Fig. 5A); however, the ratio of p-AKT to t-AKT was significantly higher in sorafenib-resistant liver cancer cells compared with parental cells (Fig. 5A), while there was no significant difference in JNK activity (the ratio of p-JNK to t-JNK) between the two groups (Fig. 5A). The AKT inhibitor BEZ-235 significantly reduced the expression of c-jun and FoxM1, and inhibited the activity of AKT (the ratio of p-AKT to t-AKT), without an effect on JNK (the ratio of p-JNK to t-JNK) in sorafenib-resistant liver cancer cells (Fig. 5B). However, the JNK inhibitor SP600125 inhibited the activity of JNK (the ratio of p-JNK to t-JNK), but had no effect on the expression of c-jun and FoxM1 in sorafenib resistance in liver cancer cells (Fig. 5C). The AKT inhibitor BEZ-235 also significantly reduced the resistance of sorafenib-resistant liver cancer cells to sorafenib (Fig. 5D). These results indicated that the activation of AKT stimulated the c-jun/FoxM1 axis in sorafenib-resistant liver cancer cells.

AKT inhibition and FoxM1 knockdown increases sorafenib sensitivity of sorafenib-resistant liver cancer cells in vivo. To investigate the effect of AKT inhibition and FoxM1 knockdown on sorafenib resistance, sorafenib-resistant liver cancer cells or FoxM1-knockdown sorafenib-resistant liver cancer cells were implanted under the skin of nude mice. As revealed in Fig. 6A and B, tumors derived from sorafenib-resistant liver cancer cells were fast growing, even when treated with sorafenib. While treatment with sorafenib combined with BEZ-235, or sorafenib treatment together with FoxM1 knockdown significantly delayed tumor growth (Fig. 6A and B). Western blot and qPCR analyses revealed that BEZ-235 and FoxM1 siRNA reduced the level of FoxM1 in tumor tissues, at both the protein and mRNA levels (Fig. 6C and D). BEZ-235 treatment also reduced the expression of c-jun (Fig. 6C). These results demonstrated that AKT inhibition or FoxM1 silencing increased the sorafenib sensitivity of sorafenib-resistant liver cancer cells in vivo.

\section{Discussion}

The clinical approval of sorafenib has been marked as a new era in molecular targeted therapy for advanced liver cancer (21). However, a phenomenon termed 're-treatment response' has been increasingly observed (4). For example, certain patients have a positive initial response to sorafenib treatment, but treatment failure occurs over time. The acquired resistance of cancer drugs remains a critical obstacle in cancer therapy. The molecular mechanism of sorafenib resistance is still poorly understood. The aim of the 

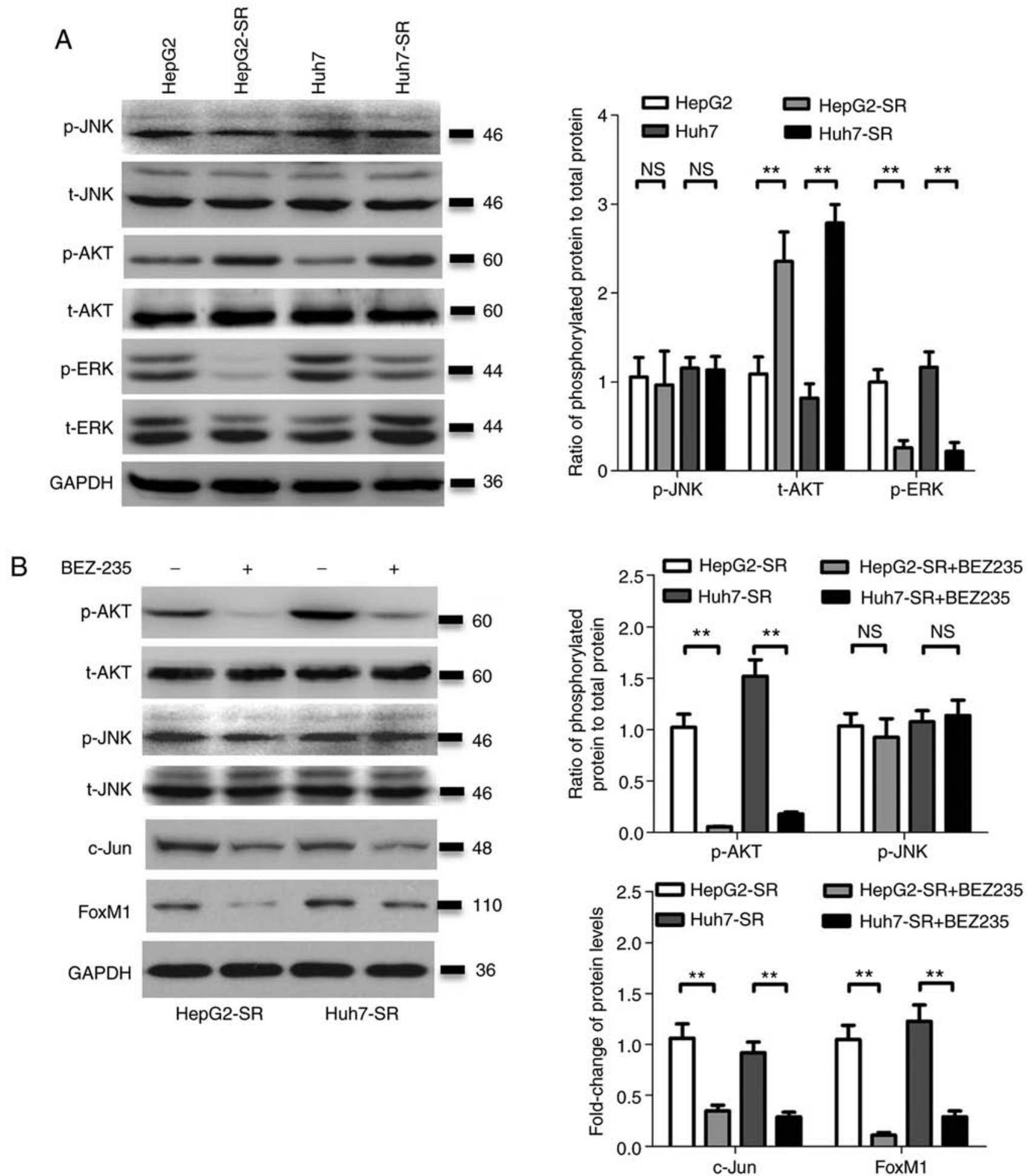

Figure 5. AKT activates the c-jun/FoxM1 axis in sorafenib-resistant liver cancer cells. (A) The protein levels of p-JNK, t-JNK, p-AKT, t-AKT, p-ERK and t-ERK were detected by western blotting, and the ratios of p-JNK/t-JNK, p-AKT/t-AKT and p-ERK/t-ERK were calculated after quantification using Quantity One software in HepG2/HepG2-SR and HuH-7/Huh7-SR cells. (B) HepG2-SR and Huh7-SR cells were treated with vehicle control or BEZ-235 $(50 \mathrm{nM})$ for $24 \mathrm{~h}$, then the protein levels of p-AKT, t-AKT, p-JNK, t-JNK, c-Jun and FoxM1 were detected by western blotting, and the ratios of p-JNK/t-JNK, p-AKT/t-AKT, c-Jun/GAPDH and FoxM1/GAPDH were calculated after quantification using Quantity One software.

present study was to investigate the molecular mechanisms of acquired resistance to sorafenib.

The forkhead box family consists of $>50$ mammalian proteins, including FoxM1. FoxM1 is important for various biological processes, such as proliferation, migration, metabolism and invasion (15). As an oncogenic transcription factor, FoxM1 expression is upregulated in various types of cancer, including liver cancer (22). Previous studies have demonstrated that FoxM1 is a key regulator of cell cycle progression. The activation of FoxM1 has been revealed to be closely associated with the activation of cell proliferation, invasion, migration and tumorigenesis (23). Furthermore, 


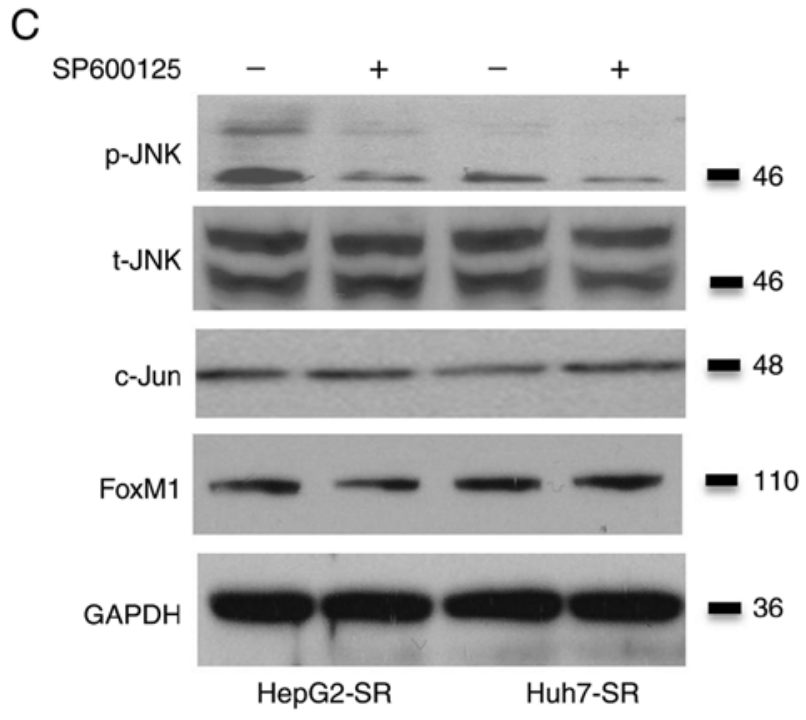

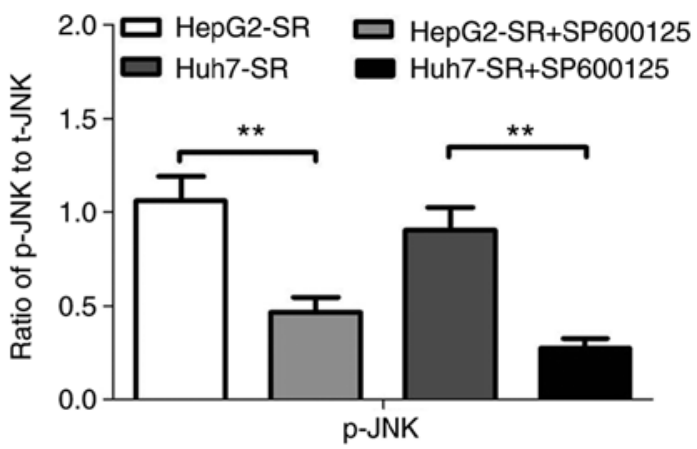

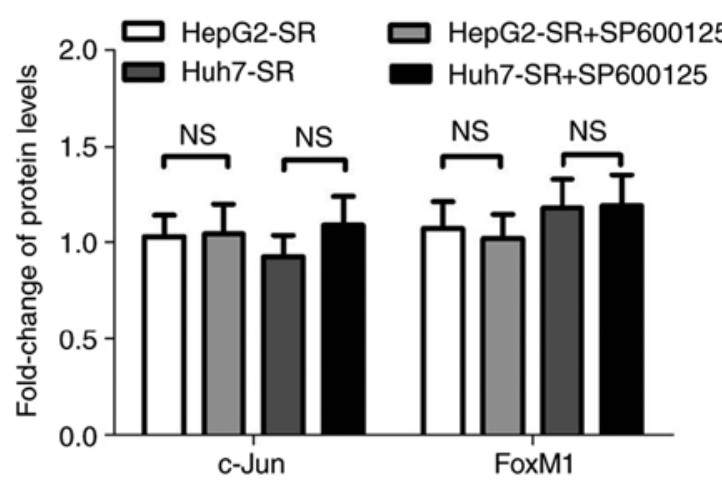

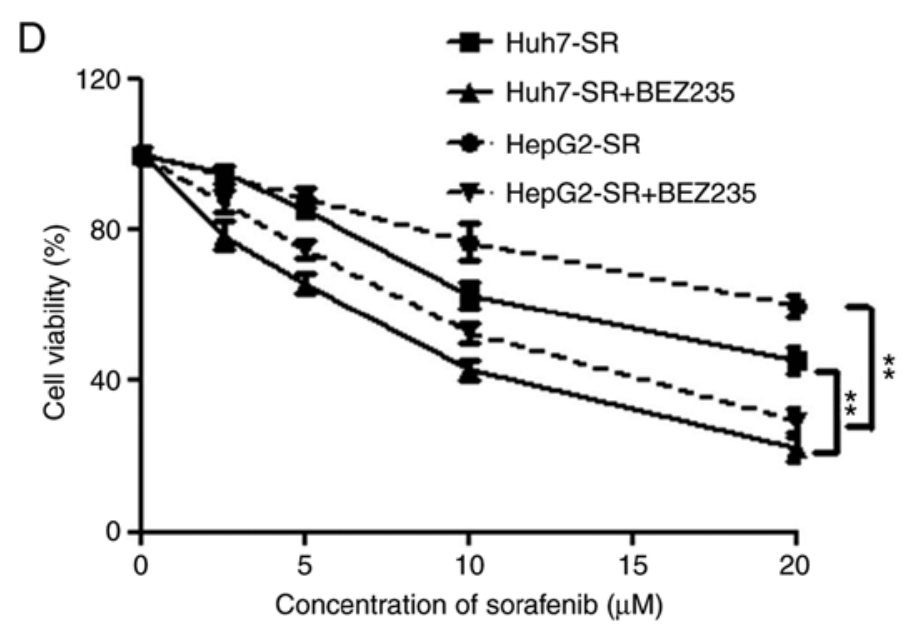

Figure 5. Continued. (C) HepG2-SR and Huh7-SR cells were treated with vehicle control or SP600125 (10 $\mu \mathrm{M})$ for $24 \mathrm{~h}$, then the protein levels of p-JNK, t-JNK, c-jun and FoxM1 were detected by western blotting, and the ratios of p-JNK/t-JNK, c-Jun/GAPDH and FoxM1/GAPDH were calculated after quantification using Quantity One software. (D) HepG2-SR and Huh7-SR cells were treated with vehicle control or BEZ-235 (50 nM), combined with sorafenib at increasing concentrations for $48 \mathrm{~h}$. Then the cell viability was measured by CCK- 8 kit. The experiment presented is representative of at least three independent experiments. ${ }^{* *} \mathrm{P}<0.01$. FoxM1, forkhead box M1; p-, phosphorylated-; ns, not significant.

the deletion of FoxM1 results in cell cycle arrest and mitotic spindle damage in vitro, and loss of FoxM1 leads to lethal embryonic effects in vivo. FoxM1 is also an important molecular target in drug-resistant tumors. Suppression of FoxM1 can sensitize tumor cells to drug treatment $(16,17)$. The combination of chemotherapeutic regimens and FoxM1 inhibition may reduce treatment side effects, and lead to the use of lower effective doses in patients. These studies suggest that FoxM1 is an attractive target for liver cancer therapy. Moreover, recent research has indicated that the overexpression of FoxM1 predicts poor prognosis in patients with liver cancer after resection (24). A previous study revealed that sorafenib reduces the expression of FoxM1 in liver cancer cells (25). Our unpublished data also revealed that sorafenib treatment rapidly downregulates FoxM1 in HepG2 and Huh7 cells; however, FoxM1 was significantly upregulated in sorafenib-resistant liver cancer cells treated with sorafenib for $>1$ month. These results indicated that FoxM1 was downregulated initially, followed by upregulation as liver cancer cells become resistant to sorafenib.

Multiple factors and various mechanisms regulate the expression and activity of FoxM1. FoxM1 is regulated by microRNAs (miRs), including miR-214 (26), miR-197 (27), miR-34a (28), miR-361-5p (29), miR-761 (30) and miR-216b (31), and long non-coding RNAs, such as LINC00339 (32), LOC653786 (19), ubiquitin-specific protease 5 (33), ubiquitin-conjugating enzyme E2C (34) and ubiquitination E3-ligase RNF168 (35). FoxM1 is transcriptionally regulated by c-Myc (36), Her-2 (37), hypoxia-inducible factor (HIF)-1 $\alpha$ and HIF-2 $\alpha$ (38); however, it is currently unclear 
A

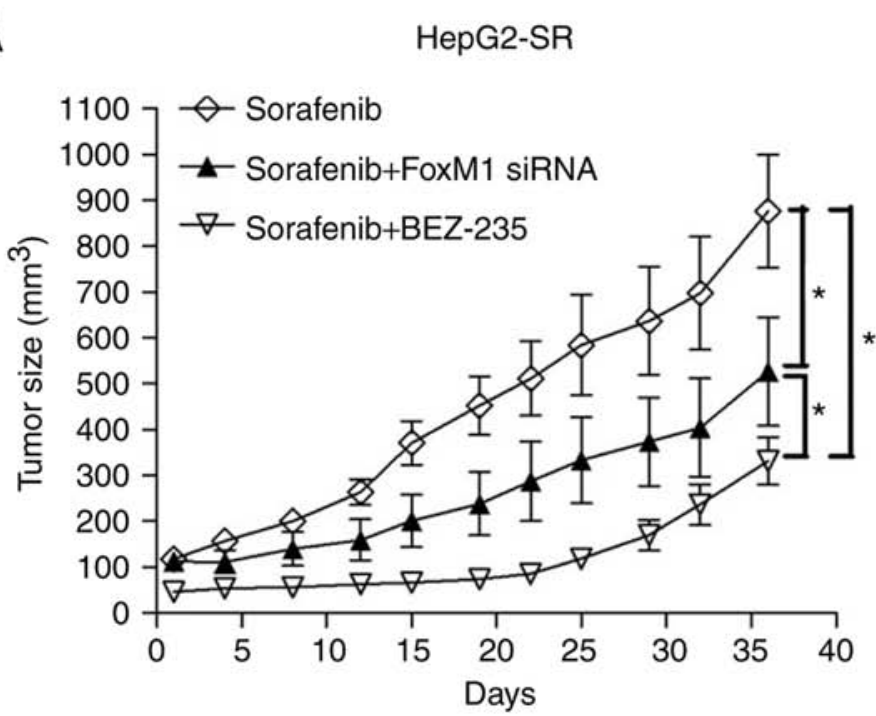

Huh7-SR

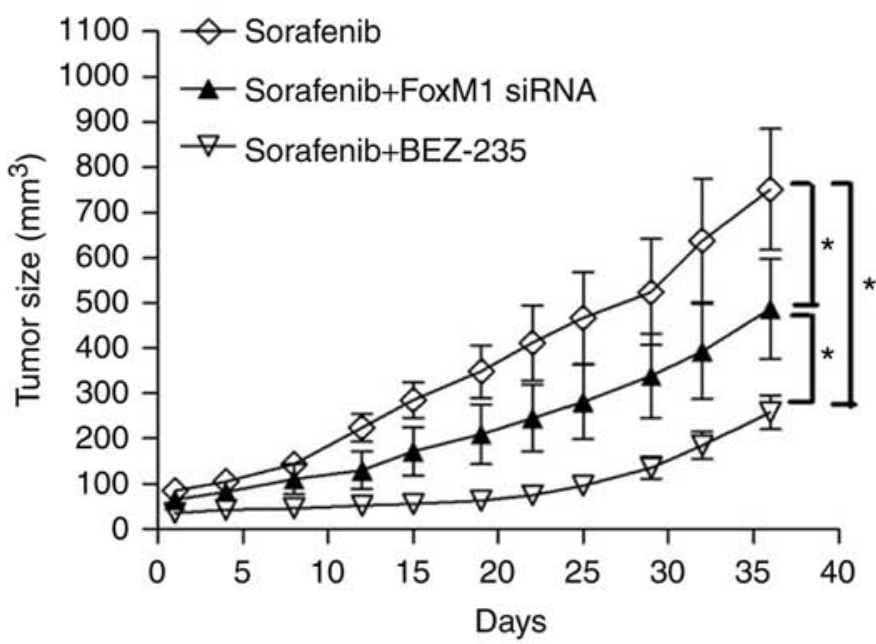

B
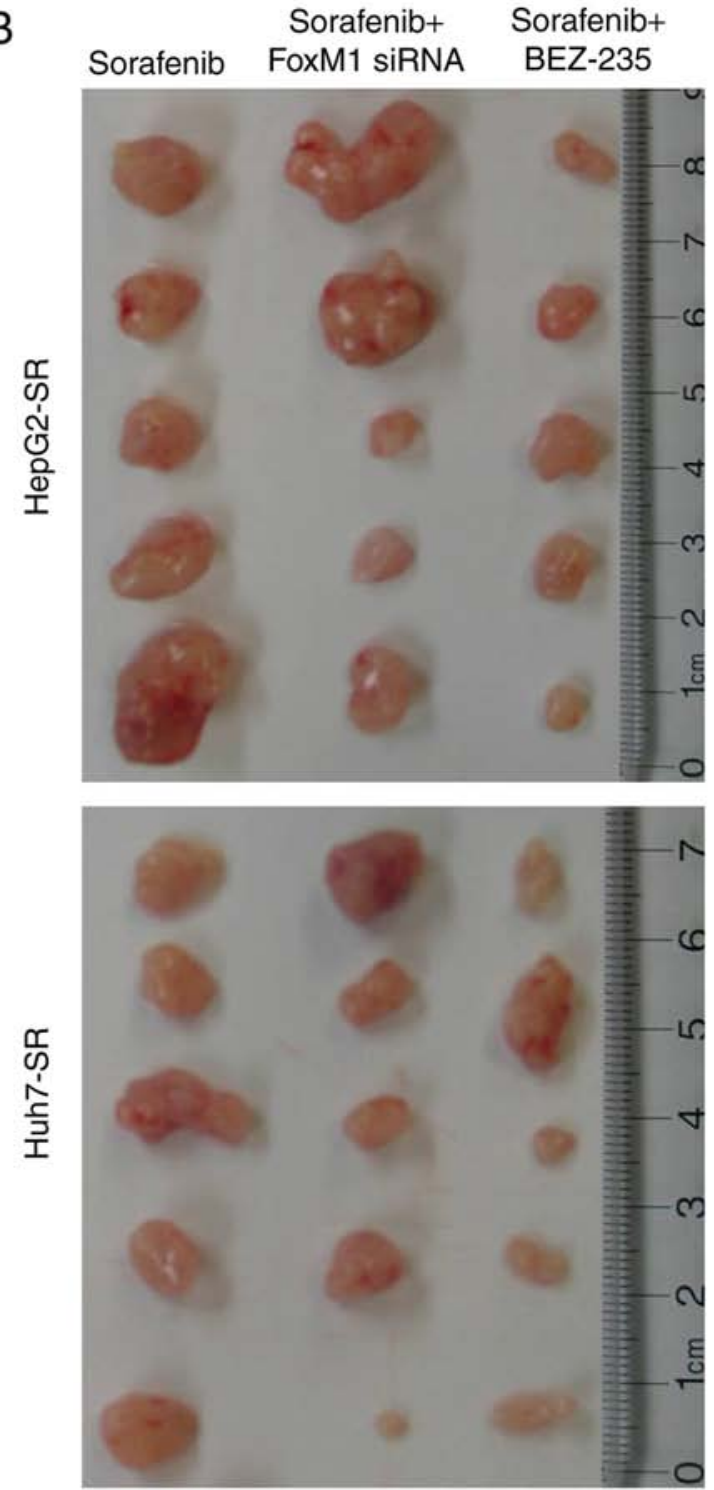

Figure 6. AKT inhibition and FoxM1 knockdown increases the sensitivity of sorafenib-resistant liver cancer cells to sorafenib in vivo. (A) HepG2-SR/Huh7-SR or HepG2-SR/Huh7-SR transfected with FoxM1 siRNA cells $\left(2 \times 10^{6}\right)$ were subcutaneously injected into the flanks on both sides of each mouse. When the tumors reached $\sim 100 \mathrm{~mm}^{3}$, the mice were randomized into 5-8 mice per group. BEZ-235 (12.5 mg/kg), sorafenib (30 mg/kg), or combined BEZ-235 and sorafenib were administrated daily via oral gavages. The data presented are average tumor size. * $\mathrm{P}<0.05$. (B) The tumor xenografts of each group were obtained after treatment for 36 days.

whether FoxM1 is regulated by AP1. The present study demonstrated that FoxM1 upregulation mediated by AP1 promotes sorafenib resistance in liver cancer cells. AP1 can bind to the -608 to -618 site of the FoxM1 promoter and induce the transcription of FoxM1.

The dimeric activator protein 1 (AP-1) transcription factor family mainly consists of Jun (c-Jun, JunB and JunD) and Fos proteins (c-Fos, FosB, Fra-1 and Fra-2) (39). c-Jun is expressed as an immediate early gene in response to a variety of stress stimuli, growth factors and subsequent signaling through MAP kinase pathways. It is a major determinant of cell fate in the liver (40). Moreover, c-Jun acts as an oncogene in the liver and strongly promotes liver tumorigenesis in models of chemically-induced HCC (41). Consistent with a previous study (42), the present study revealed that the overexpression of c-Jun contributed to sorafenib resistance in liver cancer cells. Generally, c-Jun is activated after phosphrylation by
JNK. Notably, in the present study it was revealed that JNK inhibition did not change the level of c-Jun. Since the levels of p-JNK between parental cells and sorafenib-resistant cells did not exhibit significant differences, thus it is surmised that the JNK/c-Jun pathway does not play a key role in sorafenibresistant cells.

The PI3K/AKT signaling pathway is involved in hepatocarcinogenesis and chemoresistance in liver cancer cells (43-45). The AKT inhibitor PI-103 was revealed to enhance the inhibitory effects of sorafenib on cell proliferation and tumorigenesis in liver cancer cells (46). The AKT inhibitor MK-2206 was revealed to reverse the multidrug resistance and epithelial-mesenchymal transition phenotype in sorafenib-resistant liver cancer cells (44). Inhibition of the PI3K/AKT signaling pathway using LY294002 can also reverse sorafenib-derived chemoresistance in liver cancer (47). AKT pathways activate various transcription 
C
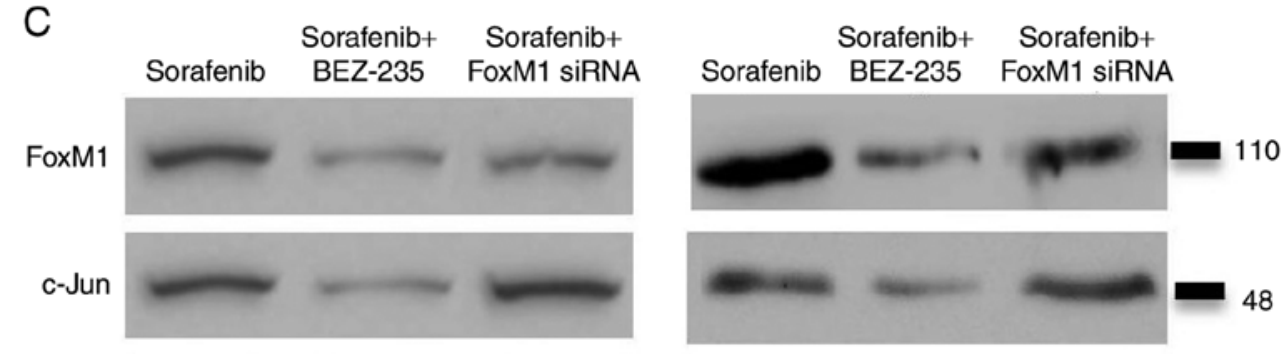

GAPDH

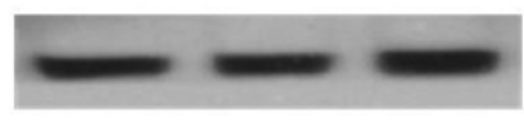

HepG2-SR

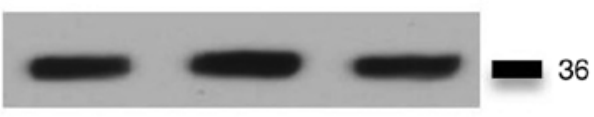

Huh7-SR
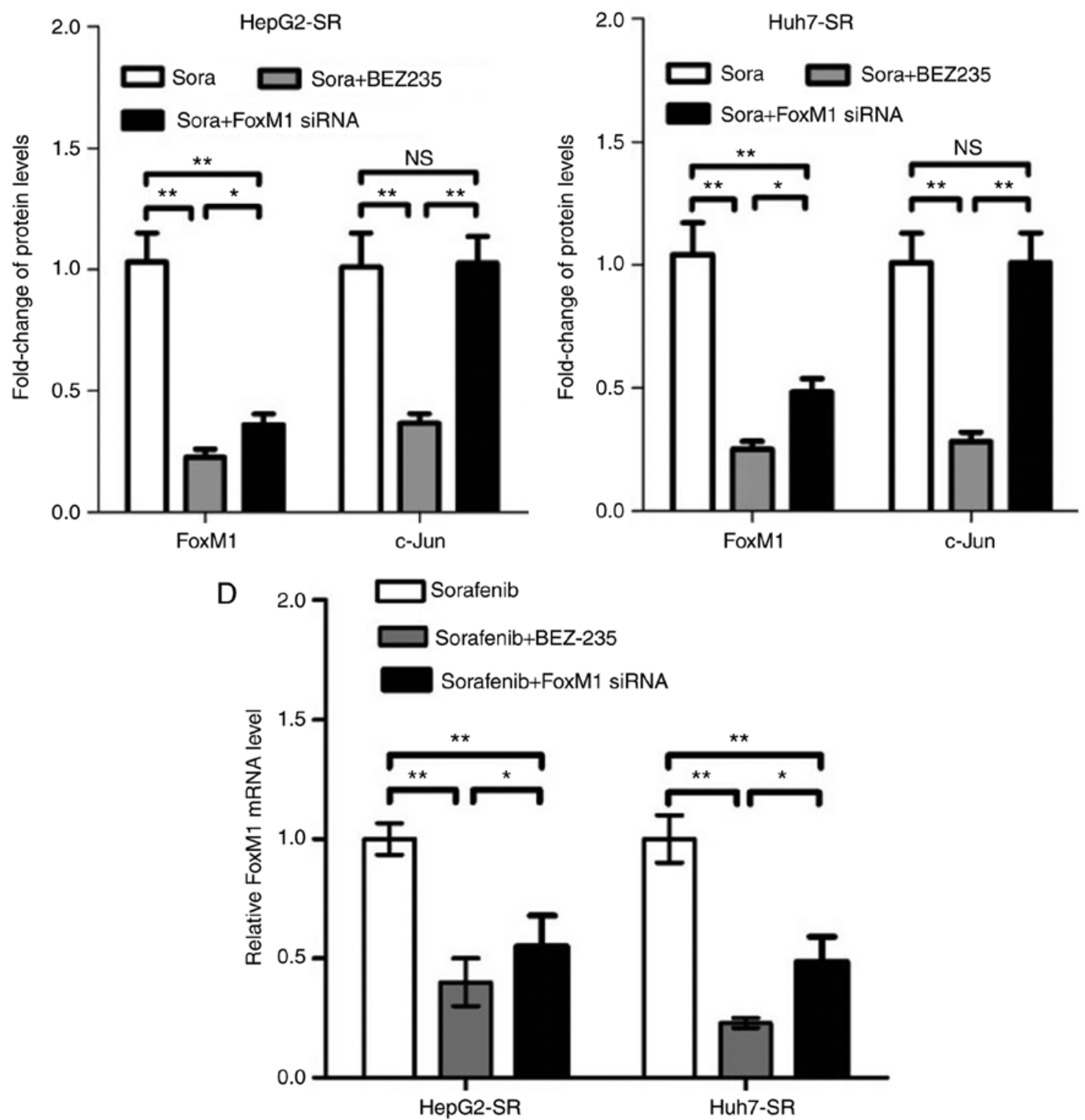

Figure 6. Continued. (C) The levels of c-jun and FoxM1 in xenograft tumor tissue lysates from indicated groups were detected by immunoblotting and quantified using Quantity One software after treatment for 1 week. The experiment presented is representative of at least three independent experiments. $\mathrm{P}<0.05$ and ${ }^{* *} \mathrm{P}<0.01$. (D) The mRNA level FoxM1 in xenograft tumor tissue lysates from indicated groups were detected by qPCR after treatment for 1 week. The experiment presented is representative of at least three independent experiments. ${ }^{*} \mathrm{P}<0.05$ and ${ }^{* *} \mathrm{P}<0.01$. FoxM1, forkhead box $\mathrm{M} 1$; ns, not significant.

factors, including AP1 (48). Consistent with the previous studies, the findings of the present study demonstrated that the PI3K/AKT signaling pathway was activated in sorafenib-resistant liver cancer cells, followed by AP1 activation. The AKT/AP1/FoxM1 signaling axis also contributed to sorafenib resistance. Suppression of this axis by BEZ-235 significantly reduced sorafenib resistance in liver cancer cells in vitro and in vivo. 
In summary, the present study highlights an important molecular mechanism of sorafenib resistance in liver cancer cells. Targeting the AKT/AP1/FoxM1 signaling axis may overcome sorafenib resistance in patients with liver cancer.

\section{Acknowledgements}

Not applicable.

\section{Funding}

The present study was supported by the National Natural Science Foundation of China (grant nos. 81460558 and 81572375) and the Chongqing Natural Science Foundation (cstc2018jcyjA2018).

\section{Availability of data and materials}

The datasets and certain material used and/or analyzed during the present study are available from the corresponding author on reasonable request.

\section{Authors' contributions}

JL and WC conceived and designed the experiments. DY, XY and XD performed the experiments. JL and WC wrote the manuscript. LC, LS, TL and FH ordered the reagents, collected the materials and analyzed the data. All authors read and approved the final manuscript and agree to be accountable for all aspects of the research in ensuring that the accuracy or integrity of any part of the work are appropriately investigated and resolved.

\section{Ethics approval and consent to participate}

All animal experiments were performed according to the protocol approved by the Army Medical University Guidelines for Use and Care of Animals.

\section{Patient consent for publication}

Not applicable.

\section{Competing interests}

The authors declare that they have no conflict of interests.

\section{Referrences}

1. Khemlina G, Ikeda S and Kurzrock R: The biology of Hepatocellular carcinoma: Implications for genomic and immune therapies. Mol Cancer 16: 149, 2017.

2. Lee DH and Lee JM: Primary malignant tumours in the non-cirrhotic liver. Eur J Radiol 95: 349-361, 2017.

3. Eso Y and Marusawa H: Novel approaches for molecular targeted therapy against hepatocellular carcinoma. Hepatol Res 48: 597-607, 2018.

4. Ray EM and Sanoff HK: Optimal therapy for patients with hepatocellular carcinoma and resistance or intolerance to sorafenib: Challenges and solutions. J Hepatocell Carcinoma 4: 131-138, 2017.

5. Yao S, Fan LY and Lam EW: The FOXO3-FOXM1 axis: A key cancer drug target and a modulator of cancer drug resistance. Semin Cancer Biol 50: 77-89, 2018.

6. Frau M, Feo F and Pascale RM: Pleiotropic effects of methionine adenosyltransferases deregulation as determinants of liver cancer progression and prognosis. J Hepatol 59: 830-841, 2013.
7. Wang IC, Chen YJ, Hughes D, Petrovic V, Major ML, Park HJ, Tan Y, Ackerson T and Costa RH: Forkhead box M1 regulates the transcriptional network of genes essential for mitotic progression and genes encoding the SCF (Skp2-Cks1) ubiquitin ligase. Mol Cell Biol 25: 10875-10894, 2005.

8. Wang Z, Ahmad A, Li Y, Banerjee S, Kong D and Sarkar FH: Forkhead box M1 transcription factor: A novel target for cancer therapy. Cancer Treat Rev 36: 151-156, 2010.

9. Laoukili J, Stahl M and Medema RH: FoxM1: At the crossroads of ageing and cancer. Biochim Biophys Acta 1775: 92-102, 2007.

10. Ma RY, Tong TH, Leung WY and Yao KM: Raf/MEK/MAPK signaling stimulates the nuclear translocation and transactivating activity of FOXM1. Methods Mol Biol 647: 113-123, 2010.

11. Balli D, Zhang Y, Snyder J, Kalinichenko VV and Kalin TV: Endothelial cell-specific deletion of transcription factor FoxM1 increases urethane-induced lung carcinogenesis. Cancer Res 71: 40-50, 2011.

12. Zhang Y, Zhang N, Dai B, Liu M, Sawaya R, Xie K and Huang S: FoxM1B transcriptionally regulates vascular endothelial growth factor expression and promotes the angiogenesis and growth of glioma cells. Cancer Res 68: 8733-8742, 2008.

13. Wang Z, Banerjee S, Kong D, Li Y and Sarkar FH: Down-regulation of Forkhead Box M1 transcription factor leads to the inhibition of invasion and angiogenesis of pancreatic cancer cells. Cancer Res 67: 8293-8300, 2007.

14. Tan Y, Raychaudhuri P and Costa RH: Chk2 mediates stabilization of the FoxM1 transcription factor to stimulate expression of DNA repair genes. Mol Cell Biol 27: 1007-1016, 2007.

15. Myatt SS and Lam EW: The emerging roles of forkhead box (Fox) proteins in cancer. Nat Rev Cancer 7: 847-859, 2007.

16. Kwok JM, Peck B, Monteiro LJ, Schwenen HD, Millour J, Coombes RC, Myatt SS and Lam EW: FOXM1 confers acquired cisplatin resistance in breast cancer cells. Mol Cancer Res 8: 24-34, 2010.

17. Carr JR, Park HJ, Wang Z, Kiefer MM and Raychaudhuri P: FoxM1 mediates resistance to herceptin and paclitaxel. Cancer Res 70: 5054-5063, 2010.

18. Sebaugh JL: Guidelines for accurate EC50/IC50 estimation. Pharm Stat 10: 128-134, 2011.

19. Yang F, Wu Q, Zhang Y, Xiong H, Li X, Li B, Xie W, Zhang L, $\mathrm{Xu}$ M, Zhang $\mathrm{K}$ and He F: LncRNA LOC653786 promotes growth of RCC cells via upregulating FOXM1. Oncotarget 9: 12101-12111, 2018.

20. Zhai B, Hu F, Jiang X, Xu J, Zhao D, Liu B, Pan S, Dong X, Tan G, Wei Z, et al: Inhibition of Akt reverses the acquired resistance to sorafenib by switching protective autophagy to autophagic cell death in hepatocellular carcinoma. Mol Cancer Ther 13: 1589-1598, 2014.

21. da Motta Girardi D, Correa TS, Crosara Teixeira M and Dos Santos Fernandes G: Hepatocellular carcinoma: Review of targeted and immune therapies. J Gastrointest Cancer 49: 227-236, 2018.

22. Wu QF, Liu C, Tai MH, Liu D, Lei L, Wang RT, Tian M and Lü Y: Knockdown of FoxM1 by siRNA interference decreases cell proliferation, induces cell cycle arrest and inhibits cell invasion in MHCC-97H cells in vitro. Acta Pharmacol Sin 31: 361-366, 2010.

23. Qu K, Xu X, Liu C, Wu Q, Wei J, Meng F, Zhou L, Wang Z, Lei L and Liu P: Negative regulation of transcription factor FoxM1 by p53 enhances oxaliplatin-induced senescence in hepatocellular carcinoma. Cancer Lett 331: 105-114, 2013.

24. Sun H, Teng M, Liu J, Jin D, Wu J, Yan D, Fan J, Qin X, Tang H and Peng Z: FOXM1 expression predicts the prognosis in hepatocellular carcinoma patients after orthotopic liver transplantation combined with the Milan criteria. Cancer Lett 306: 214-222, 2011.

25. Wei JC, Meng FD, Qu K, Wang ZX, Wu QF, Zhang LQ, Pang Q and Liu C: Sorafenib inhibits proliferation and invasion of human hepatocellular carcinoma cells via up-regulation of p53 and suppressing FoxM1. Acta Pharmacol Sin 36: 241-251, 2015.

26. Tian C, Wu H, Li C, Tian X, Sun Y, Liu E, Liao X and Song W: Downreguation of FoxM1 by miR-214 inhibits proliferation and migration in hepatocellular carcinoma. Gene Ther 25: 312-319, 2018.

27. Hu Q, Du K, Mao X and Ning S: miR-197 is downregulated in cervical carcinogenesis and suppresses cell proliferation and invasion through targeting forkhead box M1. Oncol Lett 15: 10063-10069, 2018. 
28. Segal NH,He AR, Doi T, Levy R, Bhatia S, Pishvaian MJ, Cesari R, Chen Y, Davis CB, Huang B, et al: Phase I study of single-agent utomilumab (PF-05082566), a 4-1BB/CD137 agonist, in patients with advanced cancer. Clin Cancer Res 24: 1816-1823, 2018.

29. Tian L, Zhao Z, Xie L and Zhu J: MiR-361-5p suppresses chemoresistance of gastric cancer cells by targeting FOXM1 via the PI3K/Akt/mTOR pathway. Oncotarget 9: 4886-4896, 2017.

30. Cao S, Lin L, Xia X and Wu H: MicroRNA-761 promotes the sensitivity of colorectal cancer cells to 5-Fluorouracil through targeting FOXM1. Oncotarget 9: 321-331, 2017.

31. He S, Liao B, Deng Y, Su C, Tuo J, Liu J, Yao S and Xu L: MiR-216b inhibits cell proliferation by targeting FOXM1 in cervical cancer cells and is associated with better prognosis. BMC Cancer 17: 673, 2017.

32. Yuan Y, Haiying G, Zhuo L, Ying L and Xin H: Long non-coding RNA LINC00339 facilitates the tumorigenesis of non-small cell lung cancer by sponging miR-145 through targeting FOXM1. Biomed Pharmacother 105: 707-713, 2018.

33. Li XY, Wu HY, Mao XF, Jiang LX and Wang YX: USP5 promotes tumorigenesis and progression of pancreatic cancer by stabilizing FoxM1 protein. Biochem Biophys Res Commun 492: 48-54, 2017

34. Guo L, Ding Z, Huang N, Huang Z, Zhang N and Xia Z: Forkhead Box M1 positively regulates UBE2C and protects glioma cells from autophagic death. Cell Cycle 16: 1705-1718, 2017.

35. Kongsema M, Zona S, Karunarathna U, Cabrera E, Man EP Yao S, Shibakawa A, Khoo US, Medema RH, Freire R and Lam EW: RNF168 cooperates with RNF8 to mediate FOXM1 ubiquitination and degradation in breast cancer epirubicin treatment. Oncogenesis 5: e252, 2016.

36. Pan H, Zhu Y, Wei W, Shao S and Rui X: Transcription factor FoxM1 is the downstream target of c-Myc and contributes to the development of prostate cancer. World J Surg Oncol 16: 59, 2018

37. Qi W, Li X, Zhang Y, Yao R, Qiu W, Tang D and Liang J: Overexpression of Her-2 upregulates FoxM1 in gastric cancer. Int J Mol Med 33: 1531-1538, 2014.

38. Bai C, Liu X, Qiu C and Zheng J: FoxM1 is regulated by both HIF- $1 \alpha$ and HIF- $2 \alpha$ and contributes to gastrointestinal stromal tumor progression. Gastric Cancer 22: 91-103, 2019.

39. Eferl R and Wagner EF: AP-1: A double-edged sword in tumorigenesis. Nat Rev Cancer 3: 859-868, 2003.
40. Fuest M, Willim K, Macnelly S, Fellner N, Resch GP, Blum HE and Hasselblatt P: The transcription factor c-Jun protects against sustained hepatic endoplasmic reticulum stress thereby promoting hepatocyte survival. Hepatology 55: 408-418, 2012.

41. Min L, Ji Y, Bakiri L, Qiu Z, Cen J, Chen X, Chen L, Scheuch H, Zheng H, Qin L, et al: Liver cancer initiation is controlled by AP-1 through SIRT6-dependent inhibition of survivin. Nat Cell Biol 14: 1203-1211, 2012.

42. Haga Y, Kanda T, Nakamura M, Nakamoto S, Sasaki R, Takahashi K, Wu S and Yokosuka O: Overexpression of c-Jun contributes to sorafenib resistance in human hepatoma cell lines. PLoS One 12: e0174153, 2017.

43. Kunter I, Erdal E, Nart D, Yilmaz F, Karademir S, Sagol O and Atabey N: Active form of AKT controls cell proliferation and response to apoptosis in hepatocellular carcinoma. Oncol Rep 31: 573-580, 2014.

44. Dong J, Zhai B, Sun W, Hu F, Cheng H and Xu J: Activation of phosphatidylinositol 3-kinase/AKT/snail signaling pathway contributes to epithelial-mesenchymal transition-induced multi-drug resistance to sorafenib in hepatocellular carcinoma cells. PLoS One 12: e0185088, 2017.

45. Zhang PF, Li KS, Shen YH, Gao PT, Dong ZR, Cai JB, Zhang C, Huang XY, Tian MX, Hu ZQ, et al: Galectin-1 induces hepatocellular carcinoma EMT and sorafenib resistance by activating FAK/PI3K/AKT signaling. Cell Death Dis 7: e2201, 2016.

46. Gedaly R, Angulo P, Chen C, Creasy KT, Spear BT, Hundley J, Daily MF, Shah M and Evers BM: The role of PI3K/mTOR inhibition in combination with sorafenib in hepatocellular carcinoma treatment. Anticancer Res 32: 2531-2536, 2012.

47. Zhang $\mathrm{H}$, Wang $\mathrm{Q}$, Liu $\mathrm{J}$ and $\mathrm{Cao} \mathrm{H}$ : Inhibition of the PI3K/Akt signaling pathway reverses sorafenib-derived chemo-resistance in hepatocellular carcinoma. Oncol Lett 15: 9377-9384, 2018.

48. Kumar D, Tewari-Singh N, Agarwal C, Jain AK, Inturi S, Kant R, White CW and Agarwal R: Nitrogen mustard exposure of murine skin induces DNA damage, oxidative stress and activation of MAPK/Akt-AP1 pathway leading to induction of inflammatory and proteolytic mediators. Toxicol Lett 235: $161-71,2015$ 